P

оль энАоте иина-1 и и аутоантител к нему в патогенезе атопического дерматита: исследование случай-контроль

(C) Кибалина И.В. ${ }^{*}$, Цыбиков Н.Н.

Читинская государственная медицинская академия

672027, Россия, г. Чита, ул. Горького, д. 39А

Обоснование. Атопический дерматит - хронический мультифракториальный дерматоз, имеющий сложную патофризиологическую основу. Одним из малоизученных звеньев патогенеза заболевания является эндотелин-1. К его основным биологическим эфффектам относят выраженную вазоконстрикцию сосудов.

Цель настоящего исследования заключалась в изучении роли эндотелина-1 и аутоантител к нему в патогенезе атопического дерматита.

Материал и методы. В исследование были включены 40 пациентов с распространенной и ограниченной формами атопического дерматита в период обострения и ремиссии. Определение концентрации эндотелина-1 и аутоантител к нему в сыворотке крови проводили методом ИФА. Для статистической обработки полученных данных применяли программный пакет Statistica 6.0. Статистическую значимость определяли при $p<0,05$.

Результаты. Высокие концентрации эндотелина-1 и аутоантител к нему определялись в период обострения заболевания. При разрешении клинической картины концентрация эндотелина-1 и аутоантител к нему достоверно снижалась, однако оставалась выше показателей группы контроля.

На основании полученных нами данных можно предположить, что повышение концентрации эндотелина-1 является маркером белого дермографризма и регулятором процесса микроциркуляции в коже. Заключение. Высокий уровень эндотелина-1 способствует развитию воспалительных реакций в коже, белого дермографизма и кожного зуда. Рецепторы к эндотелину-1 могут быть потенциальными мишенями для таргетной терапии атопического дерматита.

Ключевые слова: эндотелин-1, аутоантитела, атопический дерматит, дермографизм, зуд.

Конфрликт интересов: авторы данной статьи подтвердили отсутствие конфрликта интересов, о котором необходимо сообщить.

Источник финансирования: научная работа выполнена за счет средств ФГБОУ ВО «Читинская государственная медицинская академия» Минздрава России, г. Чита, РФ.

Для цитирования: Кибалина И.В., Цыбиков Н.Н. Роль эндотелина-1 и аутоантител к нему в патогенезе атопического дерматита: исследование случай-контроль. Вестник дерматологии и венерологии. 2021;97(1):34-40. doi: https://doi.org/10.25208/vdv478 


\title{
1 he role of endothelin-1 and its autoantibodies in the pathogenesis of atopic dermatitis: a case-control study
}

\author{
(C) Irina V. Kibalina*, Namzhil N. Tsybikov
}

Chita State Academy of Medicine

Gorkogo str., 39A, 672027, Chita, Russia

Background. Atopic dermatitis is a chronic multifactorial dermatosis with a complex pathophysiological basis. One of the poorly studied links in the pathogenesis of the disease is endothelin-1. Its main biological effects include pronounced vasoconstriction of blood vessels.

Aim. To study the role of endothelin-1 and its autoantibodies in the pathogenesis of atopic dermatitis.

Materials and methods. The study included 40 patients with common and limited forms of atopic dermatitis in the period of exacerbation and remission. The concentration of endothelin-1 and autoantibodies to it in the blood serum was determined by the ELISA method. Statistical processing of the obtained data was performed using Statistica 6.0. Statistical significance was determined at $p<0.05$.

Results. High concentrations of endothelin-1 and autoantibodies to it were determined during the exacerbation of the disease. When the clinical picture was resolved, the concentration of endothelin-1 and autoantibodies to it significantly decreased, but remained higher than the control group. Based on the data obtained, it can be assumed that an increase in the concentration of endothelin-1 may be a marker of white dermographism and a regulator of the microcirculation process in the skin.

Conclusions. A high level of endothelin-1 contributes to the development of inflammatory reactions in the skin, white dermographism and itching. Endothelin-1 receptors may be potential aim for targeted therapy of atopic dermatitis.

Keywords: endothelin-1, autoantibodies, atopic dermatitis, dermographism, itch.

Conflict of interest: the authors of this article confirmed the absence of a conflict of interest, which should be reported.

Source of funding: the study was carried out at the expense of financial resources of the Chita State Medical Academy of the Ministry of Health of the Russian Federation, Chita, Russia.

For citation: Irina V. Kibalina, Namzhil N. Tsybikov. The role of endothelin-1 and its autoantibodies in the pathogenesis of atopic dermatitis: a case-control study. Vestnik Dermatologii i Venerologii. 2021;97(1):34-40.

doi: https://doi.org/10.25208/vdv478 
Атопический дерматит (АД) - мультифакториальный генетически детерминированный дерматоз со сложной патофизиологической основой и характерной возрастной клинической картиной. В настоящее время среди всех хронических дерматозов распространенность АД составляет до 30\%. Заболевание обычно возникает в детском возрасте, протекая хронически со сменой периодов обострения и ремиссии.

В патогенезе АД важную роль играют дисбаланс Т-хелперов 1-го и 2-го типов с характерным цитокиновым профилем, образование IgE c последующей дегрануляцией тучных клеток, что приводит к возникновению воспалительных изменений в коже [1-3]. Значимую патогенетическую роль в развитии АД может играть эндотелин-1 (ЭТ-1). Вещество синтезируется эндотелиальными и гладкомышечными клетками сосудов, астроцитами и нейронами, гепатоцитами, тканевыми базофилами и культивированными кератиноцитами. ЭТ-1 образуется за короткий период времени при участии адреналина, цитокинов, ангиотензина-II, после механического воздействия и не способен накапливаться в клетках [4]. Известно, что увеличению синтеза ЭТ-1 способствует трансфрормирующий фрактор роста $\beta$, снижение концентрации регулируется аутоантителами и аутоантителами-абзимами [5-9]. Изначально ЭТ-1 был признан самым мощным вазоконстриктором, но в настоящее время известно, что он обладает многими другими биологическими свойствами [10-12]. В литературе описаны прямые и опосредованные эффекты ЭТ-1, реализующиеся через активацию эндотелин-А рецепторов, экспрессируемых миоцитами сосудистой стенки, кардиомиоцитами, клетками головного мозга и желудочно-кишечного тракта, и эндотелин-В рецепторов, локализующихся в гладкомышечных клетках сосудов среднего и мелкого диаметра, почках, желудочно-кишечном тракте [13]. По современным литературным данным, незначительные концентрации ЭТ-1 напрямую активируют рецепторы эндотелия с высвобождением фракторов релаксации и опосредованно через аутокринно-паракринные реакции с высвобождением медиаторов, таких как оксид азота, простациклин, натрийуретический пептид, способствуют вазодилатации, однако увеличение его уровня активирует рецепторы гладкомышечных клеток, вызывая вазоспазм и пролиферацию средней оболочки мелких артерий $[14,15]$. Таким образом, в зависимости от концентрации ЭТ-1 запускает антагонистические реакции.

Проведены исследования, показавшие влияние биологически активных веществ тучных клеток слизистых оболочек крысы на синтез ЭТ-1 и ингибирование экспрессии цитокинов. Доказано, что в кожных покровах ЭТ-1 участвует в синтезе меланина через механизмы активации тирозиназы [16]. Кроме этого, ЭТ-1 может играть важную роль в модулировании синтеза цитокинов путем регуляции их продукции лимфоцитами, активирует митогенез, пролиферативные изменения клеток, фииброз интимы сосудистой стенки [17-19]. ЭТ-1 участвует в развитии удушья при бронхиальной астме, вызывая отек тканей и гиперреактивность бронхов аэроаллергенам, активирует хемотаксис нейтрофилов, увеличивает миграцию в очаг воспаления нейтрофилов, способствует синтезу провоспалительных цитокинов и коллагеназы, приводя к гипертрофии гладких мышц бронхиального дерева, гиперплазии эпителиоцитов, фриброзу базальной мембраны, одна- ко очень мало данных о его участии в патогенезе АД [20]. В связи со сказанным представляется актуальным определить уровень ЭТ-1 и аутоантител к нему при АД.

Цель настоящего исследования заключалась в изучении роли ЭТ-1 и аутоантител к нему в патогенезе АД.

\section{Методы}

Дизайн исследования

Уровень ЭТ-1 и аутоантител к нему исследовался в плазме крови у пациентов с АД и в контрольной группе. Обследование пациентов проводилось в период обострения заболевания до терапии, после окончания терапии и в период ремиссии. Тип исследования - случай-контроль.

\section{Критерии соответствия}

Критериями включения пациентов в исследование являлись: наличие диагноза АД, стаж заболевания более 2 лет, наличие подписанного добровольного информированного согласия, отсутствие сопутствующих заболеваний, в том числе хронических, в стадию ремиссии. Критериями исключения являлись: сопутствующие хронические заболевания в анамнезе, проведение лекарственной терапии (НПВС, Н1-блокаторы, системные и топические глюкокортикостероиды, циклоспорины, ингибиторы кальциневрина) и/или общей узкополосной средневолновой ультрафиолетовой терапии в течение 2 месяцев до включения пациента в исследование, беременность и лактация, клинические признаки вторичного инфицирования кожи, длительность ремиссии АД менее 2 месяцев после купирования обострения заболевания в рамках исследования.

Условия проведения

Исследование проводилось на базе ГУЗ «Краевой кожно-венерологический диспансер» Минздрава Забайкальского края (г. Чита) и ФГБОУ ВО «Читинская государственная медицинская академия» Минздрава России (г. Чита).

\section{Продолжительность исследования}

В статье представлены предварительные результаты исследования, полученные в период с 2015 по 2018 г.

Описание медицинского вмешательства

Обследование пациентов проводилось трижды: 1) во время обострения АД до начала терапии заболевания, 2) после проведенного в стационаре курса лекарственного лечения или ультрафииолетового облучения кожи и 3) в период стойкой ремиссии, длившейся не менее 2 месяцев, во время которой пациенты использовали базисную терапию в виде эмолентов.

Терапия в период обострения заболевания назначалась согласно клиническим рекомендациям РОДВК по ведению больных с АД с учетом степени тяжести поражения кожи:

п гипоаллергенная диета;

- базисная терапия - эмоленты;

- системная терапия - антигистаминные препараты (клемастин, хлоропирамин, лоратадин, цетиризин), системные глюкокортикостероиды (бетаметазон, метилпреднизолон, преднизолон), циклоспорин;

наружная терапия - топические ингибиторы кальциневрина (такролимус, пимекролимус), топические глюкокортикостероиды (клобетазол, бетаметазон, триамцинолон, фрлутиказон, мометазон, метилпреднизолона ацепонат, гидрокортизона бутират, гидрокортизон), пиритион цинк, анилиновые красители (фукорцин, метиленовый синий); 
- физиотерапевтическое лечение - фототерапия (УФВ диапазон, длина волны 310-315 нм с максимумом эмиссии 311 нм).

\section{Материал и методы}

Под нашим наблюдением на базе стационарных отделений ГУЗ «Кожно-венерологический диспансер» Минздрава Забайкальского края в г. Чите находились 40 пациентов с диагнозом АД в возрасте от 18 до 40 лет: 25 (62,5\%) женщин и 15 (37,5\%) мужчин, средний возраст составил 27,4 \pm 9,5 года. В контрольную группу входили 15 здоровых добровольцев, соответствующих по полу и возрасту.

Диагностику АД проводили согласно критериям Hanifin и Rajka. Для определения степени тяжести заболевания применяли шкалу SCORAD. Оценивавшиеся значения индекса SCORAD и интенсивности зуда представлены в баллах. У каждого пациента, включенного в исследование, определялись следующие показатели: площадь поражения кожного покрова, интенсивность клинических проявлений, выраженность субъективных симптомов, таких как кожный зуд и нарушение сна. В исследовании применяли классификацию степени тяжести АД, в которой легкий АД верифицируется при индексе SCORAD менее 25 баллов, средней тяжести от 25 до 50 баллов, тяжелый - более 50 баллов [21]. Распределение обследованных пациентов в группы по интенсивности зуда осуществлялось по следующим критериям: с отсутствием зуда (0 баллов по визуальной аналоговой шкале), со слабым зудом (от 1 до 3 баллов по визуальной аналоговой шкале), с умеренным зудом (от 4 до 7 баллов по визуальной аналоговой шкале) и с интенсивным зудом (от 8 до 10 баллов по визуальной аналоговой шкале).

Максимальная длительность стационарной терапии составляла 14 койко-дней, по истечении данного периода пациенты наблюдались в амбулаторных условиях. При остаточных клинических проявлениях АД после проведенной терапии пациентам пролонгировалась наружная терапия амбулаторно до достижения ремиссии.

У всех пациентов, включенных в исследование, и у здоровых людей, составляющих контрольную группу, определяли дермографизм до терапии, после ее проведения и в период ремиссии заболевания. Забор крови производили из локтевой вены в одноразовые пробирки для забора крови Vacutainer с цитратом натрия утром натощак, центрифугировали при 3000 об/мин в течение 15 мин, полученную плазму хранили при $-70{ }^{\circ} \mathrm{C}$ до исследования. Концентрацию эндотелина-1 и аутоантител к нему в плазме измеряли методом ИФА с использованием коммерческих иммуноферментных анализов (ELISA) (Biomedica Group, Вена, Австрия) в соответствии с протоколами производителя.

Этическая экспертиза

Исследование одобрено Локальным этическим комитетом ФГБОУ ВО «Читинская государственная медицинская академия» МЗ РФ, все пациенты перед исследованием подписали добровольное информированное согласие на участие в нем.

Статистический анализ

Статистическую обработку полученных данных проводили с использованием пакетов Statistica 6.0. Статистическую значимость различий показателей в связанных выборках определяли с помощью t-критерия Стьюдента, в несвязанных выборках — U-критерия
Вилкоксона, Манна - Уитни. Корреляционный анализ между переменными проводился с помощью корреляции Пирсона и ранга Спирмена, в зависимости от распределения данных. Результаты представлены в виде среднего значения и стандартного отклонения. Статистическую значимость определяли при $p<0,05$.

\section{Результаты}

\section{Объекты (участники) исследования}

На момент включения в исследование легкая степень тяжести АД выявлена у 11 пациентов, индекс по шкале SCORAD составлял от 13 до 20, среднее значение $17,4 \pm 1,2$, после проведения терапии SCORAD равнялся нулю $(p<0,05)$. АД средней степени тяжести был диагностирован у 17 пациентов, индекс по шкале SCORAD составлял от 29 до 37 баллов, средний показатель $32,1 \pm 3,18$, после проведения терапии в данной группе пациентов значения индекса SCORAD coставляли от 1 до 3 баллов, среднее значение 1,9 0,8 $(p<0,05)$. Тяжелая степень АД была выявлена у 12 пациентов, значения индекса SCORAD в период обострения заболевания составили от 54 до 68 баллов, среднее значение $63 \pm 4,7$, после проведения терапии - от 8 до 11 баллов, среднее значение 9,3 $\pm 1,1(p<0,05)$. У всех пациентов, включенных в исследование, индекс SCORAD в период ремиссии был равен нулю.

Интенсивность кожного зуда у пациентов с атопическим дерматитом легкой степени тяжести составляла 3,2 \pm 0,6 балла, средней степени тяжести - 7,8 \pm 1,1 балла, тяжелой степени - 9,4 \pm 0,1 балла. При АД легкой степени тяжести у 9,09\% пациентов отсутствовал кожный зуд, у 27,2\% пациентов выявлен слабый кожный зуд, у 63,71\% - умеренный кожный зуд. Среди пациентов с распространенной формой АД, характеризовавшегося средней тяжестью поражения кожи, выделены 2 группы интенсивности кожного зуда: у 76,4\% больных определен умеренный зуд, 23,6\% пациентов страдали от интенсивного кожного зуда. При тяжелой степени все пациенты субъективно ощущали постоянный интенсивный кожный зуд.

Основные результаты исследования

Первые результаты в период проведения терапии фиксировались в виде полного регресса субъективного ощущения кожного зуда, в период ремиссии данный симптом отсутствовал у всех пациентов. В группе исследования до проведения терапии белый дермографризм был выявлен у 32 пациентов (80\%), смешанный у 8 человек (20\%). После окончания терапии 29 человек (72,5\%), страдающих АД, имели белый дермографизм, 11 - смешанный $(27,5 \%)$. В период ремиссии длительностью не менее 2 месяцев белый дермографизм наблюдался у 6 человек (15\%), смешанный у 26 (65\%) и красный у 8 пациентов (20\%). В контрольной группе в 100\% случаев был определен красный дермографизм (рисунок).

Включенные в исследование пациенты с ограниченной формой АД имели легкую степень тяжести заболевания, распространенный кожный процесс был выявлен у пациентов со среднетяжелой и тяжелой степенями тяжести АД. Уровень ЭТ-1 в плазме крови в период обострения легкого АД составил 0,44 \pm 0,15 фммоль/мл, при АД средней степени тяжести - 0,63 $\pm 0,17$ фммоль/мл, при тяжелом АД - 0,94 \pm 1,2 фмоль/мл. Уровень ЭТ-1 в плазме крови больных АД как легкой, так и средней степени тяжести был достоверно выше по сравнению 


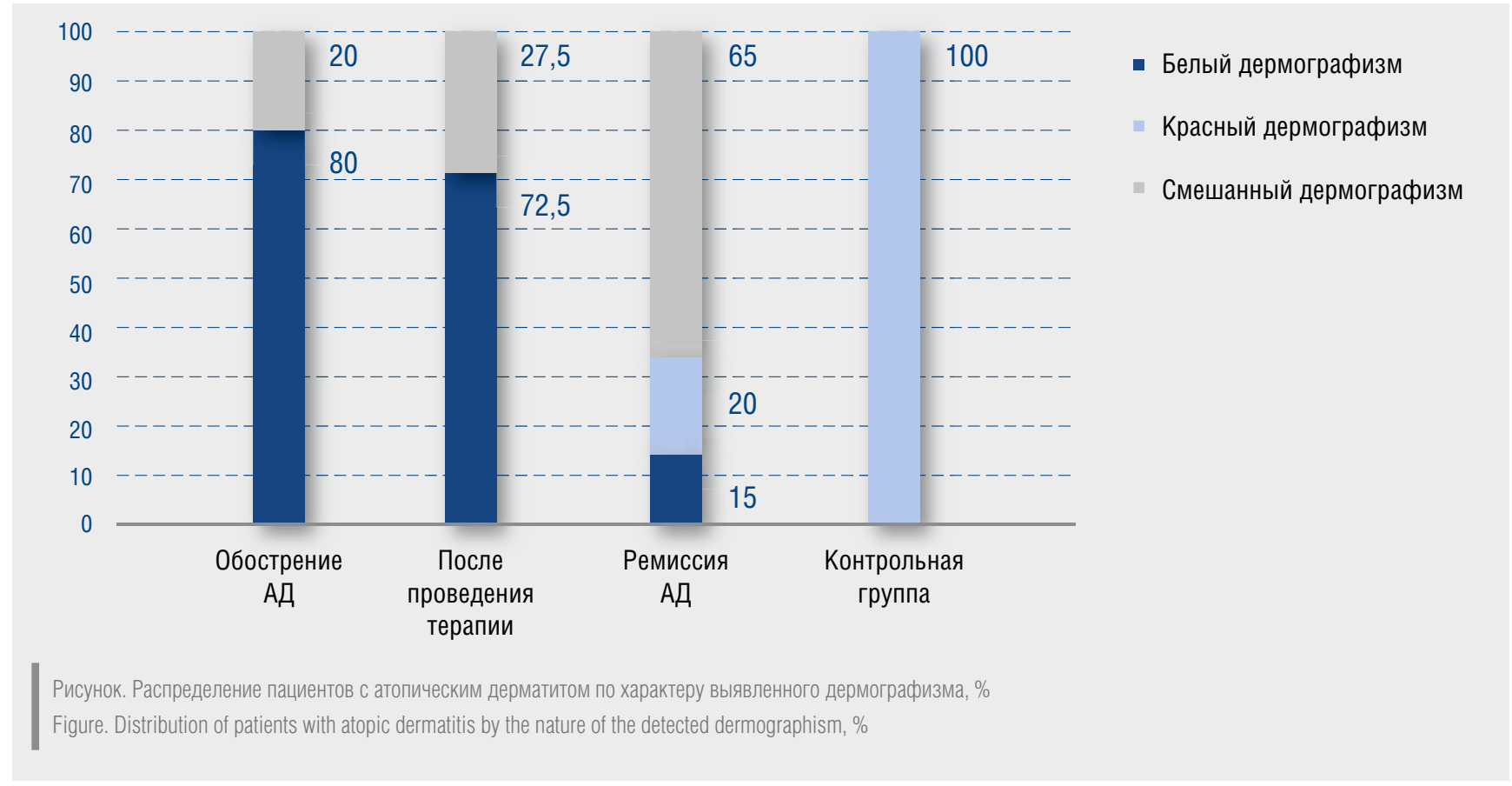

с контрольной группой $-0,34 \pm 0,11$ фмоль/мл $(p<0,05)$ (табл.). После проведенной терапии концентрация ЭТ-1 достоверно уменьшилась по сравнению с исходным уровнем, который отмечался при обострении заболевания, и составила при легком АД 0,38 $\pm 0,18$ фмоль/мл, при среднетяжелом АД - 0,36 \pm 0,21 фрмоль/мл, при тяжелом АД $-0,37 \pm 0,11$ фрмоль/мл $(p<0,05)$. В период ремиссии заболевания уровень ЭТ-1 был сопоставим с показателями, выявленными в контрольной группе. Уровень эндотелина-1 в период ремиссии в крови больных легким АД составил 0,33 \pm 0,10 фмоль/мл, АД сред- ней тяжести - 0,31 $\pm 0,09$ фрмоль/мл, тяжелым АД $0,33 \pm 0,10$ фрмоль/мл.

Значимые корреляционные связи обнаружены между уровнем ЭT-1 в плазме крови и шкалой SCORAD $(r=0,52 ; p<0,05)$, а также между концентрацией ЭТ-1 и тяжестью зуда $(r=0,64 ; p<0,05)$ в период обострения заболевания.

\section{Нежелательные явления}

Нежелательных явлений отмечено не было на этапе как стационарного, так и амбулаторного ведения пациентов.

Таблица. Содержание эндотелина-1 и антител к нему в крови у больных атопическим дерматитом в соответствии со степенью тяжести, оцененной по индексу SCORAD Table. The concentration of endothelin-1 and antibodies to it in the blood of patients with atopic dermatitis in accordance with the severity of the disease and the SCORAD index

\begin{tabular}{|c|c|c|c|c|c|c|c|c|c|c|}
\hline \multirow{3}{*}{ Показатели } & \multirow{2}{*}{\multicolumn{3}{|c|}{$\begin{array}{c}\text { Легкий АД }(n=11) \\
\text { ограниченная форма }\end{array}$}} & \multicolumn{3}{|c|}{ Среднетяжелый АД ( $n=17)$} & \multicolumn{3}{|c|}{ Тяжелый АД ( $n=12)$} & \multirow{3}{*}{$\begin{array}{c}\text { Контрольная } \\
\text { группа } \\
(n=15)\end{array}$} \\
\hline & & & & \multicolumn{6}{|c|}{ распространенная форма } & \\
\hline & обострение & после терапии & ремиссия & обострение & после терапии & ремиссия & обострение & после терапии & ремиссия & \\
\hline $\begin{array}{c}\text { SCORAD, } \\
\text { среднее } \\
\text { значение, } \\
\text { баллы }\end{array}$ & $17,4 \pm 1,2^{\star}$ & $\begin{array}{l}0 \\
\dagger\end{array}$ & $\begin{array}{l}0 \\
\dagger\end{array}$ & $32,1 \pm 3,18$ & $1,9 \pm 0,8^{*}$ & 0 & $63 \pm 4,7$ & $9,3 \pm 1,1^{\star}$ & $\begin{array}{l}0 \\
\dagger\end{array}$ & 0 \\
\hline $\begin{array}{l}\text { Интенсив- } \\
\text { ность зуда, } \\
\text { баллы }\end{array}$ & $3,2 \pm 0,6^{\star} \dagger^{\star *}$ & 0 & 0 & $7,8 \pm 1,1^{*}$ & 0 & 0 & $9,4 \pm 0,1^{*}$ & 0 & $0^{\dagger}$ & 0 \\
\hline $\begin{array}{c}\text { ЭТ-1, } \\
\text { фмоль/мл }\end{array}$ & $0,44 \pm 0,15^{*}$ & $0,38 \pm 0,18$ & $0,33 \pm 0,10^{\dagger}$ & $0,63 \pm 0,17^{\star *}$ & $0,36 \pm 0,2$ & $0,31 \pm 0,09^{\dagger}$ & $0,94 \pm 1,2$ & $0,37 \pm 0,11^{\dagger}$ & $0,33 \pm 0,10^{\dagger}$ & $0,34 \pm 0,11$ \\
\hline $\begin{array}{l}\text { AT IgG } \\
\text { к ЭТ-1, } \\
\text { мКг/мЛ }\end{array}$ & $38,21 \pm 0,13 \ddagger^{* *}$ & $18,43 \pm 3,09^{*}$ & $20,40 \pm 1,06$ & $49,31 \pm 3,21^{* * *}$ & $19,84 \pm 6,15^{\dagger}$ & $20,06 \pm 0,32$ & $63,52 \pm 5,48^{*}$ & $20,40 \pm 1,06^{\dagger}$ & $21,45 \pm 2,16$ & $22,50 \pm 2,73$ \\
\hline
\end{tabular}

* - статистически значимая разница при сравнении с контрольной группой; $†$ статистически значимая разница при сравнении с уровнем показателя до лечения; - с статистически значимая разница при сравнении с показателем в группе больных с атопическим дерматитом средней степени тяжести; ${ }^{* *}$ - статистически значимая разница при сравнении с показателем в группе больных с тяжелым атопическим дерматитом.

* - statistically significant difference when compared with the control group; $\dagger$ - statistically significant difference when compared with the level of the indicator before treatment; $\ddagger$ - statistically significant difference when compared with the indicator in the group of patients with moderate atopic dermatitis; ** — statistically significant difference when compared with the indicator in the group of patients with severe atopic dermatitis. 


\section{Обсуждение}

Резюме основного результата исследования

Нами показано, что в период обострения АД происходит увеличение уровня ЭТ-1, и его концентрация снижается в период разрешения клинической картины заболевания. Кроме этого, мы выявили значимые корреляционные связи в период выраженной клинической симптоматики между концентрацией ЭТ-1 в плазме крови, тяжестью заболевания и интенсивностью кожного зуда.

Обсуждение основного результата исследования

Патофизиология зуда при АД до конца не изучена, однако существует несколько механизмов его возникновения. Известно, что внутриклеточная нейральная пептидаза-1 была идентифицирована как ключевой регулятор ЭТ-1 зависимого кожного зуда [22]. Существует теория возникновения кожного зуда, в основе которой лежит выброс гистамина из дегранулированных тучных клеток, однако она несовершенна, так как антигистаминные препараты не всегда оказывают противозудное действие, обуславливая торпидность к лечению дерматоза. Однако мы предполагаем, что при дегрануляции тучных клеток выделяются молекулы гистамина, связывающиеся со специфическим рецептором на поверхности эндотелиальной клетки, вызывая ее сокращение, что приводит к активации синтеза ЭТ-1 с последующим проявлением его биологических эффректов.

Одним из диагностических критериев АД является белый дермографизм - стойкий вазоспазм, возникающий в результате активации симпатической нервной системы. Однако проведенные нами исследования показали, что в патогенезе заболевания важную роль поддержания и усугубления воспалительных изменений в коже играет ЭТ-1 [23, 24]. Можно предположить, что маркером белого дермографизма при АД является повышение уровня ЭТ-1 в плазме крови. При механическом воздействии на кожу при проверке дермографризма эндотелиальными клетками сосудов происходит активный выброс ЭТ-1 и возникает местный спазм сосудов микроциркуляторного русла. Возможно, эозинофилы и поврежденные при АД кератиноциты кожи способствуют синтезу ЭТ-1, вызывающего вазоконстрикцию, что, на наш взгляд, может влиять на нарушение микроциркуляции в коже, усугубляя воспалительные реакции с последующим синтезом метаболитов арахидоновой кислоты и образованием кислых продуктов обмена веществ, которые, взаимодействуя с рецепторами кожи, вызывают зуд. Возможно, при снижении концентрации ЭТ-1 кровоток в сосудах дермы восстанавливается, проявление белого дермографизма исчезает, улучшается микроциркуляция в сосудах дермы и регрессирует симптом кожного зуда.

Мы считаем, что аутоантитела к ЭТ-1 при АД являются регуляторами биологической активности вазоконстрикторов, непосредственно участвующих в процессах микроциркуляции кожи. Повышенные концентрации ЭТ-1 могут усугублять воспалительные процессы в коже и, возможно, приводить к появлению вторичной альтерации и гиперпигментации у пациентов с АД. Мы предполагаем, что в период ремиссии повышение концентрации аутоантител к ЭТ-1 является маркером скорого обострения заболевания. Однако элиминация ЭТ-1 может быть обеспечена аутоантителами в чрезвычайно короткие сроки для поддержания нормального функционирования поверхностной и глубокой сосудистых сетей дермы.

\section{Ограничения исследования}

Факторов, способных существенным образом повлиять на выводы исследования, не выявлено.

\section{Заключение}

Нами впервые исследован уровень ЭТ-1 и выявлены аутоантитела к нему при АД. Мы предполагаем, что в патогенезе заболевания ЭТ-1 не только ограничивает очаг воспаления, реализуя биологический эффект через вазоспазм, но и усугубляет тяжесть заболевания, способствуя нарушению микроциркуляции в коже. Кроме этого, повышение концентрации ЭТ-1 в плазме крови может являться маркером белого дермографизма и кожного зуда. При подтверждении патофизиологической роли ЭТ-1 при АД в последующих клинических исследованиях рецепторы к ЭТ-1 могут быть потенциальными мишенями для таргетной терапии АД.

\section{Литература/References}

1. Guttman-Yassky E, Nograles K, Krueger JG. Contrasting pathogenesis of atopic dermatitis and psoriasis - Part I: Clinical and pathologic concepts. J Allergy Clin Immunol. 2011;127(8):1110.

\section{doi: 10.1016/j.jaci. 2011.01.053}

2. Wu LC, Zarrin AA. The production and regulation of $\lg E$ by the immune system. Nat Rev Immunol. 2014;14(4):247-259. doi: 10.1038/nri3632

3. Tsybikov NN, Petrisheva IV, Fefelova EV, et al. Plasma a-defensins are elevated during exacerbation of atopic dermatitis. Clin Exp Dermatol. 2016;41(3):253-259. doi: 10.1111/ced. 12767

4. Willey KE, Davenport AP. Nitricoxide - medulation of the $\mathrm{E}-1$ signaling path way in cardiovascular system. $\mathrm{Br} \mathrm{J}$ Pharmacol. 2001;132:213-220. doi: 10.1038/sj.bjp.0703834

5. Tsybikov NN, Egorova EV, Fefelova EV, et al. Biomarker assessment in chronic rhinitis and chronic rhinosinusitis: endotelin-1, TARC/CCL17, neneopepterin and $\alpha$-defensins. Allergy Asthma Proc. 2016;37(1):35-42. doi: 10.2500/aap.2016.37.3899.
6. Цыбиков Н.Н., Шовдра О.Л., Пруткина Е.В. Содержание эндотелина, нейроспецифической энолазы и аутоантител в сыворотке крови и слезной жидкости у больных сахарным диабетом 2-го типа. Вестник офтальмологии. 2010;126(4):14-16. [Tsybikov NN, Shovdra OL, Prutkina EV. The content of endothelin, neuro-specific enolase and autoantibodies in blood serum and lacrimal fluid in patients with type 2 diabetes mellitus. Bulletin of ophthalmology. 2010;126(4):14-16 (In Russ.)]

7. Цыбиков Н.Н., Заиграева Н.А., Харинцева С.В., Шовдра О.Л. Содержание нейроспецифической енолазы и аутоантител в слезной и внутриглазной жидкостях у больных с открытоугольной глаукомой (предварительное сообщение). Вестник офтальмологии. 2012;128(2):4951. [Tsybikov NN, Zaigraeva NA, Harintseva SV, Shovdra OL. The content of neuro-specific enolase and autoantibodies in lacrimal and intraocular fluids in patients with open-angle glaucoma (preliminary report). Bulletin of ophthalmology. 2012;128(2):49-51 (In Russ.)] 
8. Цыбиков Н.Н., Терешков П.П., Кузник Б.И. Аутоантитела абзимы к эндотелину-1 (1-21). Забайкальский медицинский вестник. 2011;1:100-103. [Tsybikov NN, Tereshkov PP, Kuznik BI. Autoantibodiesabzymes to endothelin-1 (1-21). Zabaykalsky medical Bulletin. 2011;1:100103 (In Russ.)]

9. Castanares C. Signaling by ALK 5 mediates TGF- $\beta$-induced ET-1 expression in endothelial cells. Journal of cell science. 2007;120:12561266. doi: $10.1242 / j c s .03419$

10. Baretella 0, Vanhoutte PM. Endothelium - Dependent contractions: prostacyclin and endothelin-1, partners in crime? Adv Pharmacol. 2016;77:177-208. doi: 10.1016/bs.apha.2016.04.006.

11. Дремина Н.Н., Шурыгин М.Г., Шурыгина И.А. Эндотелины в норме и патологии. Международный журнал прикладных и фундаментальных исследований. 2016;10(2):210-214. [Dremina NN, Shurygin MG, Shurygina IA. Endothelins in norm and pathology. International journal of applied and fundamental research. 2016;10(2):210-214 (In Russ.)]

12. Houde M, Desbiens L, D'Orleans-Juste P. Endothelin-1: biosynthesis, signaling and vasoreactivity. Adv Pharmacol. 2016;77:143175. doi: 10.1016/bs.apha.2016.05.002.

13. Гомазков О.А. Система эндотелиновых пептидов: механизмы эндоваскулярных патологий. Кардиология. 2000;1:32-39. [Gomazkov OA. System of endothelin peptides: mechanisms of cardiovascular pathologies. Cardiology. 2000;1:32-39 (In Russ.)]

14. Шурыгин М.Г., Шурыгина И.А., Каня О.В. и др. Значение повышения продукции эндотелина при инфаркте миокарда. Фундаментальные исследования. 2015;1(6):1281-1287. [Shurygin MG, Shurygina IA, Kanya OV, et al. The value of increasing endothelin production in myocardial infarction. Fundamental study. 2015;1(6):1281-1287 (In Russ.)]

15. Ikeda U. Endothelin-1 in hibits nitricoxidesyn thesis in vascular smooth muscle cells. Hypertension. 1997;29(1):65-69.

doi: 10.1161/01.hyp.29.1.65.
16. Murase D. Cooperationof endothelin-1 signaling with melanosomes plays a role in developing and/or maintaining human skin hyperpigmentation. Biol Open. 2015;4(10):1213-1221. doi: 10.1242/bio. 011973.

17. Trentin PG, Fernandes MB, D'Orleans-Juste P, Rae GA. Endothelin-1 causes pruritus in mice. Experimental biology and medicine. 2006;231(6):1146-1151.

18. Nakahara T, Kido-Nakahara M, Ohno F, et al. The pruritogenic mediator endothelin-1 shifts the dendritic cell-T-cell response toward Th17/ Th1 polarization. Allergy. 2018;73(2):511-515. doi: 10.1111/all.13322

19. Aktar MK, Kido-Nakahara M, Furue M, Nakahara T. Mutual upregulation of endothelin-1 and $\mathrm{IL}-25$ in atopic dermatitis. Allergy. 2015;70(7):846-854. doi: 10.1111/all.12633.

20. Fredberg JJ. Bronchospasm and tsbiophysical basis in airways mooth muscle. Respiratory Research. 2004;5:2-17. doi: 10.1186/1465-9921-5-2

21. Wollenberg A, Barbarot $S$, Bieber $T$, et al. Consensus-based European guidelines for treatment of atopic eczema (atopic dermatitis) in adults and children: part I. Journal of the J Eur Acad Dermatol Venereol. 2018;32(5):657-682. doi: 10.1111/jdv.14891.

22. Abassi ZA, Tate J, Golomb E, Keiser HR. Role of neutral endopeptidase in the metabolism of endothelin. Hypertension. 1992;20:8995. doi: 10.1161/01.hyp. 20.1.89.

23. Tsybikov NN, Petrisheva IV, Kuznik BI, Magen E. Plasma endothelin-1 levels during exacerbation of atopic dermatitis. Allergy Asthma Procedings. 2015;36(4):320-324. doi: 10.2500/aap.2015.36.3846.

24. Петрищева И.В., Цыбиков Н.Н., Фефелова Е.В., Терешков П.П. Уровень эндотелина-1 и $\alpha$-десензинов у пациентов с атопическим дерматитом. Клиническая дерматология и венерология. 2015;1:50-56. [Petrishcheva IV, Tsybikov NN, Fefelova EV, Tereshkov PP. The level of endothelin- 1 and $\alpha$-defensins in patients with atopic dermatitis. Clinical dermatology and venereology. 2015;1:50-56 (In Russ.)].

doi: 10.17116/klinderma2015168-70

Участие авторов: концепция и дизайн исследования, сбор и обработка материала, статистическая обработка данных, написание статьи, ее доработка и исправление - И.В. Кибалина; концепция и дизайн исследования, редактирование текста статьи, одобрение статьи для публикации - Н. Н. Цыбиков.

Authors' participation: concept and design of the research, collection and processing of the material, statistical data processing, writing of the article, its revision and correction - Irina V. Kibalina; the concept and design of the study, editing the text of the article, approval of the article for publication - Namzhil N. Cybikov.

\section{Информация об авторах}

*Ирина Владимировна Кибалина — к.м.н.; адрес: Россия, 672090, г. Чита, ул. Горького, д. 39A; ORCID iD: https://0rcid.org/0000-0003-4390183X; eLibrary SPIN: 6085-1292; e-mail: vilinia@rambler.ru

Намжил Нанзатович Цыбиков - д.м.H., профреcсор; ORCID iD: https://orcid.org/0000-0002-6192-8422; eLibrary SPIN: 1963-8418; e-mail: thybikov@mail.ru

\section{Information about the authors}

*Irina V. Kibalina — MD, Cand. Sci. (Med); address: 39A Gorkiy street, 672090, Chita, Russia; ORCID iD: https://orcid.org/0000-0003-4390-183X; eLibrary SPIN: 6085-1292; e-mail: vilinia@rambler.ru

Namzhil N. Tsybikov - MD, Dr. Sci. (Med.), Professor; ORCID iD: https://orcid.org/0000-0002-6192-8422; eLibrary SPIN: 1963-8418; e-mail: thybikov@mail.ru;

Статья поступила в редакцию: 25.06.2019

Принята к публикации: 27.01.2021

Дата публикации: 26.02.2021
Submitted: 25.06 .2019

Accepted: 27.01.2021

Published: 26.02.2021 